\title{
Nutrition and health claims in Europe: oils \& fats related claims, regulatory and labeling challenges
}

\author{
Luca Bucchini* \\ Hylobates Consulting srl, Via Tarsia 61, 00135 Rome, Italy
}

Received 21 May 2019 - Accepted 1 October 2019

\begin{abstract}
In the European Union, fats and oils in foods are regulated by laws mainly set at the Union level. EU rules on nutrition and health claims are particularly relevant for some fatty acids. Contrary to structurefunction claims in the US, in the EU, such claims have to be authorized before use; in the case of omega-3, along with a nutrition claim, a remarkable number of health claims have been authorised based on the essentiality of such fatty acids. Claims related to environmental, social or ethical concerns are not regulated in detail at the EU level. While claims are voluntary information, mandatory rules on labelling also apply to fatty acids, and sometimes create challenges for food businesses. Another piece of legislation, the novel food regulation, is important for new sources of oils and fats. Its scope includes determining the novel food status of foods, and, if required, submitting an application in order to obtain authorisation. Several sources of fatty acids have been authorized as novel foods. Benefits of a novel food application include legal certainty and protection of data, while costs and particularly the length of the process are the main barriers. An assessment of novel food status should also concern new technologies, such as new delivery mechanisms. While several provisions of EU law concern oils and fats, a 2019 regulation not only imposes a $2 \mathrm{~g}$ limit (per $100 \mathrm{~g}$ of fat) for trans fats not naturally occurring in animal fats, but also creates an obligation to transfer information in the supply chain.
\end{abstract}

Keywords: regulation / health claims / novel foods / trans-fat / omega-3

\begin{abstract}
Résumé - Allégations nutritionnelles et de santé en Europe : allégations concernant les huiles et matières grasses, réglementation et étiquetage. Dans l'Union européenne, les graisses et les huiles contenues dans les aliments sont régies par des lois principalement établies au niveau de l'Union. Les règles de l'UE sur les allégations nutritionnelles et de santé sont particulièrement pertinentes pour certains acides gras. Contrairement aux allégations structure-fonction aux États-Unis, en Europe, ces allégations doivent être autorisées avant leur utilisation; dans le cas des oméga-3, parallèlement à une allégation nutritionnelle, un nombre remarquable d'allégations relatives à la santé a été autorisé sur la base du caractère essentiel de ces acides gras. Les allégations liées à des préoccupations environnementales, sociales ou éthiques ne sont pas réglementées en détail au niveau de l'UE. Bien que les allégations soient des informations volontaires, les règles obligatoires en matière d'étiquetage s'appliquent également aux acides gras et créent parfois des difficultés pour les entreprises du secteur alimentaire. Autre élément réglementaire : le règlement dit «novel food», important pour les nouvelles sources d'huiles et de graisses. Son champ d'application comprend la détermination du statut de nouvel aliment dans les aliments et, le cas échéant, le dépôt d'une demande afin d'obtenir une autorisation. Plusieurs sources d'acides gras ont été autorisées en tant que nouveaux aliments. Les avantages d'une application novel food comprennent la sécurité juridique et la protection des données, tandis que les coûts, et en particulier la durée du processus, constituent les principaux obstacles. Une évaluation du statut des nouveaux aliments devrait également concerner les nouvelles technologies, de même que les nouveaux mécanismes de distribution. Bien que plusieurs dispositions de la législation européenne concernent les huiles et les graisses, le règlement de 2019 impose non seulement une limite de $2 \mathrm{~g}$ (pour $100 \mathrm{~g}$ de matière grasse) pour les acides gras trans qui ne sont pas naturellement présents dans les graisses animales, mais crée également une obligation de transfert d'informations dans la chaîne d'approvisionnement.
\end{abstract}

Mots clés : réglementation / allégation santé / novel foods / acides gras trans / oméga 3

\footnotetext{
*Correspondence: lucabucchini@hylobates.it
} 


\section{Introduction}

Oils and fats used in food are subject to the vast body of EU food law. Several factors determine which fats and oils reach and succeed in the marketplace; scientific advances underpin innovation in terms of the use of lipids in the food sector. Regulations are an important factor in determining which, and how, innovations reach the consumer and the food industry, and have a key role in the evolution of the marketplace. Therefore, scientists, both in academia and in industry, should have some understanding of applicable laws, as they may provide opportunities, and create barriers, to their work in both research and product development.

Of the several applicable provisions, legislation on labeling, health claims, novel foods and trans fats seems to currently have a significant bearing on the marketing and success of specific oils and fats. While national provisions continue to exist, EU law, although often challenged by national politics, provides most of the relevant rules in these respects. EU law encompasses the laws of the European Union, as well as the case-law of the Court of Justice of the European Union.

Communication on the benefits of oils and fats may be important to achieve success on the marketplace. In the European Union, communication - on labels, on e-commerce websites, and in advertising - on health benefits of foods, and of substances in food, is regulated by the Nutrition and Health Claims Regulation (NCHR), or Regulation (EC) No. 1924/ 2006. While many oils and fats are marketed without reference to nutrition or health benefits, such claims play a key role for specific sources. Health claims have been authorized for polyphenols in olive oil, and for monounsaturated and/or polyunsaturated fatty acids, as well as for foods with a low or reduced content of saturated fatty acids. Nevertheless, most authorized health claims for lipids are associated with omega-3 and omega- 6 fatty acids. Such claims represent the most interesting type of voluntary information that can be associated with fatty acids, and thus warrant a detailed discussion.

Fats and oils also have to follow rules on mandatory information. In this context, EU law provides a definition of fats, as well as rules on naming of ingredients, on allergens and other relevant matters. The nutrition declaration on labels is regulated in this context, and creates some challenges for omega-3 fatty acids. Moreover, under the presumption that foods with a significant history of consumption are likely to be safe, whereas those without warrant assessment by an independent body, the European Union has introduced legislation on novel foods in 1997. The implications for sources of fatty acids, and for some technologies, are important. The growing interest of consumers for other claims, which do not concern nutrition or health, also leads to a discussion of applicable law. Finally, in 2019, rules on trans fatty acids have been published, presenting some challenges for the food industry. The aim of this article is to review and set out the main aspects of such legislation in reference to lipids used in food.

\section{Principles applicable to health claims}

An analysis of authorized health claims for lipids should start from the core principles of applicable EU law. The key principle of Regulation (EC) No. 1924/2006 is that all claims -that is statements, images, or even implied concepts - that concern nutritional or health benefits have to be authorized before being used in the marketplace, if related to finished products for consumers. As importantly, all nutrition and health claims that have not been authorized (unless a transition period applies) are prohibited. In other words, a food business cannot simply show, when challenged, that excellent data exist in the literature to support a specific health benefit of certain fatty acids. On the contrary, the claim related to that health benefit must have been authorized by the European Commission on the basis of an assessment by the European Food Safety Authority (EFSA) before any use. An authorization process is of course not unique to claims; novel foods, food additives, or medicines all require authorization. Nevertheless, it was a new concept when introduced in 2006, and familiarity in the food industry and in the scientific community is not yet universal. Contrary to the United States, there are no exemptions for food supplements. The concept also applies to communication to professionals at least on finished products, according to the Court of Justice (judgement Verband Sozialer Wettbewerb eV v Innova Vital GmbH of 14 July 2016).

In practice, the regulation, in its annex, provides a list of nutritional claims that are authorized. On the other hand, Regulation(EU) No. 432/2012 lists most authorized health claims (some specific health claims are listed in other regulations). Claims applicable to some lipids are discussed below.

As for health claims, it is important to understand that the cornerstone of the EU law in this respect is a high level of consumer protection; according to EU law such protection can be achieved only via an independent scientific assessment of the highest possible standard. This concept, which has been validated by the General Court of the EU (judgments in The Health Food Manufacturers' Association and Others v European Commission of 12 June 2015, pp. 126-129) and is likely to withstand further legal challenge, has been interpreted by EFSA in two main ways (EFSA NDA Panel, 2016a, b): the highest possible standard can be achieved via accepted evidence on essentiality of some nutrients, and, for all other food substances, via randomized controlled human intervention trials. This has set a higher bar than the common previous practice in some Member States. Significantly, tradition does not feature in this framework, while stakeholders have expressed forcefully the view that scientifically plausible tradition is relevant at least for botanicals. As far as omega-3 and omega- 6 fatty acids are concerned, EFSA has used the concept of essentiality to assess, and give favorable opinions. According to EFSA, essentiality is "determined by knowledge of its unique ability to reverse clinical signs and symptoms of deficiency, and/or by knowledge of its essential mechanistic role in metabolic functions" (EFSA NDA Panel, 2016a). Such recognition has to be based on a large body of scientific evidence, and was a historical process. The requirements, which are met by some fatty acids, are as follows:

- the nutrient (in this case, a fatty acid) is required for normal human body function (essential mechanistic role in a metabolic function and/or it has the ability to reverse clinical signs and symptoms of its deficiency);

- the nutrient (in this case, a fatty acid) cannot be synthesised by the body, or cannot be synthesised in amounts which are adequate to maintain normal body function;

- the nutrient (in this case, a fatty acid) must be obtained from a dietary source. 
While EFSA is often praised, or criticised, for its work on claims, it is important to realize that EFSA is tasked only with evaluating the science (whether the food/substance is sufficiently characterized; whether the claimed effect is compatible with a health benefit; and, finally, whether a cause/effect relationship has been scientifically established). It is the European Commission (EC), supported by at least a majority of the Member States, to make a final decision. In fact, the EC has diverged from EFSA for public health reasons, when claims may have promoted consumption of sugars or sodium. Such claims would be against official nutrition advice and legal challenges against the EC on this topic have failed (see ruling of the General Court in Dextro Energy GmbH \& Co. KG v European Commission of 16 March 2016). A database of authorized health claims is available on the EC website, and is a useful tool for interested parties. The overall success rate of health claim applications is typically low or very low, and especially so when compared to food additives, novel foods or other articles subject to assessment; there is still a perceived lack of full predictability. In this context, the number and quality (in terms of claimed health benefits) of authorized health claims on omega- 3 and omega- 6 fatty acids is remarkable.

\section{Food information requirements}

Before detailing authorized health claims for some fatty acids, it should be noted that claims fall within the domain of voluntary food information (as opposed to mandatory food information). In fact, information on fats and oils also falls within the domain of mandatory food information. General, and detailed (though not exhaustive) rules, on food information are defined by Regulation (EU) No.1169/ 2011, including food labelling. The regulation includes a number of specific rules on fats and oils, and sets rules on "fair information practices" (article 7) that apply to claims on fat and oil properties which do not relate to health or nutrition.

Specifically, Regulation (EU) No. 1169/2011 identifies fat as a nutrient, and provides a legal definition for fat and several fatty acids. "Fat" is defined as total lipids, and includes phospholipids; "saturates" means fatty acids without a double bond; "trans fat" means "fatty acids with at least one nonconjugated (namely interrupted by at least one methylene group) carbon-carbon double bond in the trans configuration"; "mono-unsaturates" means "fatty acids with one cis double bond"; "polyunsaturates" means "fatty acids with two or more cis, cis-methylene interrupted double bonds".

The regulation also sets rules for oils and lipids which are food allergens, including processing aids, but with some exemptions. It regulates the designation of fats and oils in the ingredient list (though more specific rules may apply; on olive oil, for example). It also sets a reference (daily) intake for fats at $70 \mathrm{~g}$ per day, and, for saturates, at $20 \mathrm{~g}$ per day; this reference amount, in the context of a $2000 \mathrm{kcal}$ diet, can be quoted, under specific conditions, on labels. A conversion factor for fat to energy is also set at $37 \mathrm{~kJ} / \mathrm{g}$, or $9 \mathrm{kcal} / \mathrm{g}$.

Annex XV of the regulation describes the mandatory nutrition table ("declaration"). The regulation does not describe the graphical requirements, contrary to US rules
(21 CFR 101.9); nevertheless the order of the nutrients, and the nutrients included, are prescribed. Fat and saturates are mandatory components, and feature immediately after energy. Mono and and polyunsaturates may be selectively added after saturates.

The indication of omega-3 content is less straightforward. Omega-3 content shall be indicated when a nutrition or health claim is made on the food; however, it is not a nutrient foreseen by the mandatory nutrition declaration. If its indication is mandatory as a consequence of a claim, it shall feature in the proximity, but separated from (not within,) the nutrition declaration. These rules do not apply to food supplements, which are exempted under article 29.1.a: for food supplements, only amounts of added substances (e.g. fish oil) should be declared under article 8 of Directive 2002/46/EC (the directive does not specify a format). Some food supplements on the marketplace carry additionally a nutritional declaration as foreseen for other foods; whether this practice is compliant is debated. Doubtless however, under article 36.1 of the Regulation, if a nutritional table is provided, it should follow the Annex XV format.

\section{Nutrition and health claims on some fatty acids}

Several nutrition claims have been authorised for fatty acids. Many concern the reduction of fat or saturates. A claim that a food is "a source of omega-3 fatty acids", and any claim likely to have the same meaning for the consumer, may only be made where the product contains at least $0.3 \mathrm{~g}$ ALA ( $\alpha$-linolenic acid) per $100 \mathrm{~g}$ and per $100 \mathrm{kcal}$, or, as an alternative, at least $40 \mathrm{mg}$ of the sum of EPA (eicosaoentaenoic Acid) and DHA (docosahexaenoic acid) per $100 \mathrm{~g}$ and per $100 \mathrm{kcal}$. It should be noted that, as a consequence, alternative wording may be used (such as "contains" instead of "source"). There is a double lock on amounts, which have to be met by both mass and energy content. The "high in omega-3 fatty acids" claim can be used when the content of ALA or EPA/DHA is doubled.

When such claim are used, amounts, declared in the proximity of the nutrition declaration, should be expressed in appropriate units, in mg (EPA and DHA) or in g (ALA), depending on units in the authorised claim. Contents cannot be expressed in terms of volume, or percentage area under the curve, in either food supplements or in other foods.

In order to check the compliance with the conditions of use of the claims, the chemical form in specifications and in testing results has to be taken into account (for example, triglyceride (TG) versus free fatty acids (FFA) versus ethyl ester (EE)) for correct calculation (see GOED, 2018). Importantly, EE forms are authorised for use only in food supplements in the European Union, as they are considered unauthorised novel foods for other food uses. From article 7.2 of Regulation (EC) No. 1924/2006 (which uses the term "relates") it seems that, to assess compliance and for labelling, only DHA and EPA (or ALA) rather than total quantity of omega-3, including DPA (docosapentaenoic acid), should be considered.

The European Commission (EC, 2012) has provided guidance on tolerances and rounding of values in nutritional information. There is no guidance for omega-3, while for fats or saturates, for which a nutrition claim is made, the tolerance 
Table 1. Health claims authorised for food contents equal to the nutrition claim "source of omega-3 fatty acids" (at least $0.3 \mathrm{~g}$ ALA ( $\alpha$-linolenic acid) per $100 \mathrm{~g}$ and per $100 \mathrm{kcal}$, or, as an alternative, at least $40 \mathrm{mg}$ of the sum of EPA (eicosaoentaenoic Acid) and DHA (docosahexaenoic acid) per $100 \mathrm{~g}$ and per $100 \mathrm{kcal}$ ) in Regulation (EU) No. 432/2012. Conditions of use are indicated in the text.

\begin{tabular}{lll}
\hline Nutrient & Claim (authorised wording) & Health relationship \\
\hline Alpha-linolenic acid (ALA) & $\begin{array}{l}\text { ALA contributes to the maintenance } \\
\text { of normal blood cholesterol levels }\end{array}$ & $\begin{array}{l}\text { Maintenance of normal blood cholesterol } \\
\text { concentrations }\end{array}$ \\
$\begin{array}{l}\text { Eicosapentaenoic acid and } \\
\text { docosahexaenoic acid (EPA/DHA) }\end{array}$ & $\begin{array}{l}\text { Maintenance of normal cardiac function } \\
\text { finction of the heart } \\
\text { Linoleic acid contributes to the maintenance }\end{array}$ & $\begin{array}{l}\text { Maintenance of normal blood cholesterol } \\
\text { concentrations }\end{array}$ \\
\hline
\end{tabular}

is, on the relevant side for the claim (i.e., the beneficial side which depends on whether intake of the nutrient should be reduced, like for saturates, or increased, as for omega-3), only the measurement uncertainty. This concept may apply to omega-3 as well.

As for health claims, by definition, they are communications that state, suggest or imply that a relationship exists between a food category, a food or one of its constituents, on one side, and health on the other.

On fatty acids, health claims include the following:

- EPA/DHA: low amounts/concentration (heart health/blood cholesterol) but also LA (linoleic acid) and ALA $(\alpha$-linolenic acid);

- EPA/DHA: higher, absolute amounts;

- DHA: lower amounts (brain \& vision);

- claims for pregnancy, lactation, infants, children.

For food content equal to the amount of ALA/EPA and DHA at least required as for the nutrition claim "source of omega-3 fatty acids", the claims in Table 1 are available. One health claim is also available for LA, with the condition of at least $1.5 \mathrm{~g}$ of linoleic acid (LA) per $100 \mathrm{~g}$ and per $100 \mathrm{kcal}$, and a requirement to inform consumers that "the beneficial effect is obtained with a daily intake of $2 \mathrm{~g}$ of ALA $/ 250 \mathrm{mg}$ of EPA and DHA/10 g of LA".

It is important to understand the "wording" of authorised health claims, which is prescribed in regulations. In the case of the claim, for example, "ALA contributes to the maintenance of normal blood cholesterol levels", the constituent (food) is ALA. Therefore, the term "ALA" cannot be omitted, in the context of the claim, on labelling or advertising because the consumer should understand that the claim is linked to a specific substance, and not to the overall product. The terms "contributes to" are important because it qualifies the authorised effect, and conveys to the consumer the fact that the substance alone cannot achieve the desired health effect; therefore, "ALA maintains normal cholesterol levels" would not be compliant. The health effect is also qualified by "maintenance", which consumers should be able to tell apart from the different (and unauthorised) concept of improvement or reduction; the word "normal" has a similar meaning, and excludes pathological cholesterol levels from the health claim. Finally, "blood cholesterol levels" is the health effect, a physiological effect in reference to a function of the body. The wording can be modified in advertising as long as the original meaning is preserved in the understanding of the consumer, as noted above.

On foods which provide a daily intake of $2 \mathrm{~g}$ or $3 \mathrm{~g}$ of EPA and DHA, stronger claims are, respectively, permitted: " $D H A$ and EPA contribute to the maintenance of normal blood triglyceride levels", and "DHA and EPA contribute to the maintenance of normal blood pressure". Of the further conditions, it should be noted that when the claim is used on food supplements and/or fortified foods, information shall also be given to consumers not to exceed a supplemental daily intake of $5 \mathrm{~g}$ of EPA and DHA combined, and not to use that claim for foods targeting children.

As an example, a label of a food supplement on the market may combine the above claims, and recommend one cap for normal cardiac function (500 mg of combined EPA and DHA), four caps for normal TG ( $2 \mathrm{~g}$ of combined EPA and DHA) and six caps for blood pressure ( $3 \mathrm{~g}$ of combined EPA and DHA). It should be noted that not all Member States would accept multiple recommendations for different daily doses.

With at least $40 \mathrm{mg}$ of DHA per $100 \mathrm{~g}$ and per $100 \mathrm{kcal}$ and information to the consumer that "the beneficial effect is obtained with a daily intake of $250 \mathrm{mg}$ of $\mathrm{DHA}$ ", it can be claimed that DHA contributes to maintenance of normal brain function and normal vision.

Two further health claims are targeted at pregnant and breastfeeding women, and to children (Tab. 2).

It is noteworthy that no submission for a health claim for lipids has been made under the article 13.5 (new science) procedure, and no application is in the pipeline for assessment. Rejected claims (such as those on joints, on emotional wellbeing, or on the skin) were not resubmitted with more data. Moreover, despite their role in the diet, lipids do not have risk reduction claims (article 14).

Some botanical preparations, including oils, benefit from on-hold claims status, as foreseen under Reg. (EU) No. 432/ 2012; they can provisionally continue to be used. Nevertheless, such status is not optimal as it leads to different interpretation in the Member States

\section{Claims on bioavailability and beauty claims}

Claims, defined as any voluntary message or representation which states, suggests or implies that a food has particular characteristics, do not fall under Reg. (EC) No. 1924/2006 if 
Table 2. Health claims authorised for fatty acids and pregnancy, lactation or for children, with conditions of use.

\begin{tabular}{|c|c|c|}
\hline Nutrient & Claim (authorised wording) & Conditions of use \\
\hline Docosahexaenoic acid (DHA) & $\begin{array}{l}\text { Docosahexaenoic acid (DHA) maternal intake } \\
\text { contributes to the normal brain development } \\
\text { of the foetus and breastfed infants }\end{array}$ & $\begin{array}{l}\text { Information shall be given to pregnant and lactating } \\
\text { women that the beneficial effect is obtained with a daily } \\
\text { intake of } 200 \mathrm{mg} \text { of DHA in addition to the } \\
\text { recommended daily intake for omega- } 3 \text { fatty acids for } \\
\text { adults, i.e.: } 250 \mathrm{mg} \text { DHA and EPA. The claim can be } \\
\text { used only for food which provides a daily intake of at } \\
\text { least } 200 \mathrm{mg} \text { DHA }\end{array}$ \\
\hline
\end{tabular}

they are not nutrition or health claims. Although not subject to the authorisation requirements of health and nutrition claims, EU food law requires such voluntary claims not to be misleading, and generally meet the requirements of fair information practices, including those specific of voluntary information (article 7 and article 36 of Reg. (EU) No. 1169/ 2011). On a case by case basis, taking into account relevant case-law of the Court of Justice, it is up to food businesses and competent authorities to determine whether a claim is a stated, suggested or implied health or nutrition claim, or a different type of claim. As it is EFSA that is charged with determining whether the proposed health claims fall within the scope of the Reg. (EC) No. 1924/2006 (article 16(3)), the opinions of EFSA delivered under the Regulation provide essential technical guidance in this respect.

In 2010, the EFSA NDA Panel stated, in an opinion, that claims referring to "improved bioavailability of a nutrient rather than to a relationship between a food/food constituent and health" do not fall within the scope of Regulation (EC) No. 1924/2006. In its 2016 guidance (EFSA NDA Panel, 2016a, b), the Panel conceded that claims related to absorption of micronutrients had been evaluated by the Panel with favourable opinions; this was because improved absorption of the micronutrients was considered by the Panel as a beneficial physiological, a legal requirement for a health claim. According to the EFSA NDA Panel (2016a), absorption was a limiting factor for the maintenance of an adequate status of the nutrient, and because the absorbed nutrient could be used by the body. On this basis, other claims on bioavailability may not be considered health claims, especially in reference to the substance itself, and have to meet other requirements of food law (including being "based on the relevant scientific data", according to article $36(2)(\mathrm{c})$ ). This is the regulatory basis for claims on bioavailability also for fatty acids. Bioavailability claims may become easily comparative claims, with the attending regulatory requirements. Moreover, while some Member States of the EU accept the notion that voluntary information is permitted unless in violation of EU and national law, other Member States tend to consider such information prohibited and misleading unless explicitly permitted by law. Such claims on bioavailability may be of particular relevance to new delivery methods.

Similar reasoning has led to the emergence of the concept of beauty claims (FSE, 2014). In opinions and guidance, the EFSA NDA Panel (2012) has indicated that "claims on the maintenance of normal structure, hydration, elasticity or appearance of the skin do not necessarily refer to a particular physiological function of the skin as required by Regulation (EC) No. 1924/2006. Also a decrease in wrinkles, which may be related to the maintenance or improvement of skin structure/hydration/elasticity, does not necessarily refer to a particular physiological function of the skin as required by Regulation (EC) No. 1924/2006". In 2013, the view was formalised by the Commission and the Member States that such claims cannot be authorised as health claims, but may still be used after case-by-case assessment ("...claims on the maintenance of normal structure, elasticity, appearance and tonicity of the skin or claims on the maintenance of normal structure and appearance of hair and nails were evaluated on a case-by-case basis and they were not authorised, by virtue of Commission Regulation (EU) No.536/2013, because on the basis of the scientific evidence submitted, the European Food Safety Authority (EFSA) concluded that the claimed effect did not refer to a function of the body, as required by the Regulation. [...] Nevertheless, the Committee agreed that Member States should assess claims on a case-by-case basis, and decide whether their wording (or claimed effect) states, suggests or implies that a relationship exists between a food 
category, a food or one of its constituents and health, and therefore as falling under the scope of Regulation (EC) No. 1924/2006. Where this is not the case, still the claim should respect the general provision that the labelling, presentation or advertisement should not mislead the purchaser by attributing to the foodstuff effects or properties which it does not possess (Article 2(1)(ii) of Directive 2000/13/EC)" [the provision has since been replaced by article 7 of the FIC Regulation] (EC, 2014). The fact that a beauty effect (such as "bad breath") is not sufficient for authorising a health claim is also stated in Commission Regulation (EU) No. 1154/2014, recital 6, which also emphasised the decisive importance of EFSA NDA Panel's assessment in this context.

As consequence, the concept of beauty claim has emerged, and has since been accepted by Member States, at least in principle, in rulings by authorities in charge of overseeing advertising, and by courts. The relevant scientific data are not determined by law, but, given the aim of EU law to attain a high level of consumer protection, and the determination by EFSA that, in most cases, only data from human intervention trials would permit to attain such a level protection, suggests that beauty claims should be based on human data, unless the same criteria for essentiality of micronutrients apply. Fatty acids may have an important role in beauty and may carry beauty claims.

\section{Fatty acid sources as novel foods}

Some sources of fatty acids have not been consumed to a significant extent in the European Union before May 1997. Therefore, the so-called novel food regulation applies. In understanding the novel food legislation, it is important to realise that its primary objective is safety (as explained by the Court of Justice in Davitas GmbH. v. Stadt Aschaffenburg, 2016): its premise is the presumption of safety for foods with a significant history of consumption, which does not apply to foods which do not have such a history. While the details of its application may appear at times complex, it is important to keep in mind these guidance principles.

Determining the novel food status of a source of fatty acids - whether the source has been consumed to a significant extent - is not always a straightforward process. This determination is incumbent on the food business operator which intends to place the food on the market (article 4(1) of Regulation (EU) 2015/2283). In case of doubt, food businesses are obliged to consult the authorities of the relevant Member State. This is legally relevant as foods, which are determined novel during a control on the marketplace, are ordinarily considered not safe, and thus have to be recalled, with associated costs and implications. Manufacturers of finished products may rely on suppliers of raw materials for assessing the novel food status of ingredients, or make their own assessment; in any case, it is important to be aware that there may be liability issues if products cannot be marketed as planned due to non-compliance with the novel food regulation. A formal consultation process to determine novel food status is in place since 2018, the results of which are made public by the European Commission on its website. So far, only one finished consultation request concerns fatty acids: the cold pressed Nigella sativa Mill. seed oil. The plant, known as black caraway is an annual flowering plant in the family Ranunculaceae, and is native to south and southwest Asia. The authorities of Ireland found the oil not to be novel; the conclusion applies across the EU. Formally determining the novel food status of a raw material is useful not only for legal certainty, but also to avoid an unnecessary application (it should be noted that an application does not per se determine that a food is novel, as evidence of not novelty may emerge later or not known at the time of submission, see the ruling of the Court of Justice Mensch und Natur AG v Freistaat Bayernin of 14 Aprila 2011, p. 36).

A second important resource for determining the novel food status of food is the novel food Catalogue which is available from the Commission's website (http://ec.europa.eu/ food/safety/novel_food/catalogue/search/public/index.cfm). Among other substances, the catalogue clarifies that ethyl esters of fish oil (concentrated from fish oils) are considered unauthorised when used in foods other than food supplements; in food supplements (regulated by Directive 2002/46), they can be legally used as their use, within the food supplement category, was significant before 1997. Food supplements are the only food category to have a special status under the novel food regulation.

For foods which are indeed novel, authorisation is required, because they cannot be presumed safe. Several applications for novel foods have been submitted, and there have been several authorisations of sources of fatty acids; they are now listed in the Union list of novel foods (Commission Regulation (EU) No. 2017/2470). Tables 3 and 4 list respectively sources of DHA and EPA (in cases when EPA and DHA are listed in specifications), and sources of ALA and LA. The Union list sets the food categories in which the authorised novel foods can be used, and the related maximum amounts ("table 1" in the Union list), as well as specifications ("table 2").

In detail, different oils of Schizochytrium sp. have been authorised. The members of the genus Schizochytrium are microalgae that naturally produce DHA; the genus belongs to the kingdom Chromista. The DHA-rich oil is produced via an algal fermentation process. The first application was submitted to competent authorities of the United Kingdom in 13 February 2001 by OmegaTech $\mathrm{GmbH}$ (later acquired by Martek Biosciences Corporation), and was authorised by a Commission Decision on 5 June 2003. Subsequent applications expanded the uses of the authorised oils, and provided for authorisations of improved algal strains. Ulkenia sp. is another genus of DHA producing microalgae of the Chromista kingdom, which has been authorised as a novel food.

Several authorisations have been granted for krill oil from Euphausia superba Dana. On 29 September 2006, the company Neptune Technologies \& Bioressources Inc. made a request to the competent authorities of Finland to place a lipid extract from Antarctic Krill Euphausia superba. The authorisation was granted with Commission Decision of 12 October 2009, and several authorisations and notifications (notification was a procedure of the previous novel food regulation) followed. Other animal oils have been authorised, such as squid oil. Oil from the crustacean (marine zooplankton) Calanus finmarchicus was authorised in 2017, 5 years after the submission. 
Table 3. Authorised novel foods with a specified DHA and EPA content.



Table 4. Authorised novel foods with a specified ALA/LA content.

\begin{tabular}{|c|c|c|c|}
\hline Name & ALA/LA content & Number of food categories & Maximum amount in FS (g/day) \\
\hline Diacylglycerol oil of plant origin & $\begin{array}{l}\text { ALA } ; \leq 15 \% \\
\text { LA: } \geq 15-65 \%\end{array}$ & 7 & Not permitted \\
\hline Rapeseed oil high in unsaponifiable matter & $\begin{array}{l}\text { ALA: } 6-14 \% \\
\text { LA: } 15-28 \%\end{array}$ & 1 & $1.5 \mathrm{~g} / \mathrm{day}$ \\
\hline Sacha Inchi oil from Plukenetia volubilis & ALA: $>45 \%$ & All & Not specificed \\
\hline
\end{tabular}

As for novel foods with ALA/LA, rapeseed and maize germ oils high in unsaponifiable matter were authorised in 2006, as was diacylglycerol oil (DAG oil). On the contrary, an application for concentrated and unsaponifiable palm oil was submitted, but rapidly withdrawn, in 2003. Sources with higher ALA/LA content were authorised more recently. The oil of the seeds of Lithospermum arvense L. (also known as Buglossoides arvensis) was authorised in 2015, after a 2013 application. The plant is known as field gromwell, corn gromwell, or bastard alkanet, and is a flowering plant of the family Boraginaceae. Salvia hispanica L., known as chia, is a flowering plant in the mint family, Lamiaceae, native to central and southern Mexico and Guatemala. The seeds have been authorised as such, but also the oil was permitted in 2014 (after a 2012 application). The oil extracted from the seeds of Echium plantagineum has also been authorised in 2006. Echium oil is a source of omega- 3 and omega- 6 , although such content is not part of the specifications foreseen under EU law.

Finally, refined arachidonic-acid rich oil was authorised in 2009, while coriander seed oil was granted a positive
Commission Decision in 2014. The oil of seeds of Allanblackia (spefically, A. floribunda (synonymous with $A$. parviflora) and $A$. stuhlmannii) was also authorised in 2008 after a 2004 application. Its main benefits are technological.

All foods meeting the specifications in the Union list can be used by all food businesses under Regulation (EU) No. 2015/ 2283 , in compliance with its rules; this is in contrast with the pre-existing novel food legislation (Regulation (EEC) No. 258/ 1997) which required a new authorisation (or notification) for each business intending to place on the EU market a novel food. Under the pending applications (older regulation), an application was placed for EPA-rich oil derived from the microalgae Phaeodactylum tricornutum in 2016. Under the new regulation, applications for oils relate only to extensions of uses.

It is notable that of the several sources mentioned by Finco et al. (2017) as potentially interesting oleaginous microorganisms for omega-3 production, many are likely to be novel, and thus require authorisation. Food businesses should not see the novel food requirement simply as a barrier. Costs of 
an application may vary, and the time-scale for obtaining approvals is long (so far, in practice, two or more years). In interpreting the legal deadlines which the new regulation has meant to shorten, applicants should be aware that, while most steps have a legal deadline imposed on the Commission or EFSA, the validity check, and the agreement of Member States, steps have no legal deadline and may significantly lengthen the process. However, on top of the legal requirement, benefits of a novel food application include legal certainty across the EU, and authorisations based on proprietary data which, coupled with patents, may provide a competitive advantage. Finally, foods which have been traditionally consumed outside the EU, including potentially oils and fats, are now subject to a simpler approval process.

\section{Ethical claims and other claims}

While nutrition and health claims are heavily regulated, other claims are of increasing importance to consumers and food business. This is acknowledged in the preamble of Regulation (EU) No.1169/2011 (recital 3: “...Consumers' choices can be influenced by, inter alia, health, economic, environmental, social and ethical considerations"); so far, with the exception of organic food, claims related to environmental, social or ethical concerns do not currently have specific rules under EU law, but should conform to the general principles of "Fair information practices" (articles 7) and those applicable to voluntary information (article 36). National provisions, and legislation and case-law on unfair commercial practices (Directive 2005/29/EC), may also be relevant. Relevant claims may concern sustainability, impact on climate, and fair trade.

In reference to suitability of a food for vegetarians or vegans, article 36 of the regulation foresees specific rules; such rules have been discussed extensively and may be approved in the coming years. As omega-3 can be sourced from animals, plants, yeasts, fungi, or microalgae, and a vegan diet is increasingly popular across the EU, this would be particularly interesting. At the moment, vegetarian and vegan labelling and certification are largely based on voluntary schemes.

Claims on origin are also seen as important for consumers. With Commission Implementing Regulation (EU) $2018 / 775$, rules are in place for imposing the obligation to declare the origin of the primary ingredient (or ingredients) when the final food bears on indication of its country of origin (or of a place of provenance). Importantly, at this time, the EU does not require mandatory indication of the origin of a food, and stating or implying the country of origin is a voluntary choice. For example, if a food supplement with the claim "made in Germany" contains as a primary ingredient fish oil from Poland, the origin of the fish oil would have to be indicated as from Poland, or a disclaimer prescribed by the Regulation added. Unfortunately, the regulation, which exempts trademarks, allows for significant scope for interpretation (despite planned EU guidance) which may differ across Member States. Correct indication of the origin of raw material will be important, and may not be straightforward for some lipids.

Importantly, for claims on new delivery systems, the novel food regulation may be relevant to fats with a new molecular structure, to those obtained with a new process (under certain conditions), and to nanomaterials. When developing and marketing new technologies, such as improved delivery mechanisms, an assessment to determine novel food status is required. Food businesses should keep in mind that the novelty required for filing a patent is a trigger for a novel food assessment; while the conclusion is often that the novel food regulation does not apply, a technical assessment is required.

\section{Regulation on trans fats and other relevant aspects}

With Regulation (EU) 2019/649 of 24 April 2019, the European Commission has imposed a limit on the maximum amount of trans fat in food ("Maximum 2 grams per 100 grams of fat in food intended for the final consumer and food intended for supply to retail"). The regulation applies from April $1^{\text {st }} 2021$. Under article 2, it also imposes an obligation of food business operators, in the food supply chain, to provide information on the trans fat content of their products, if it exceeds $2 \mathrm{~g}$ in $100 \mathrm{~g}$ fat. However, food business operators will be likely asked by customers to provide information on amounts of trans fat in most cases when fat content is significant, or at least a declaration of compliance. The regulation exempts trans fats "naturally occurring in fat of animal origin", but not other trans fats of natural origin. Lipids of non-animal origin may have a content of trans fats, especially if the exemption in the Regulation is interpreted as excluding trans fats identical to those of animal origin, but manufactured industrially from plant sources. Also, while production of trans fat is normally associated with intentional hydrogenation, processing of some oils (e.g., deodorization) may lead to the unintended formation of trans fats, which is not exempt, and therefore for adequate procedures and controls. In the case of authorised novel foods, many oils have specifications for trans fatty acid content, which are equal or more restrictive than the new regulatory limits; however, some do not have specifications, and will need to comply with the new legislation. Final food manufacturers will need to implement their own checks, in a risk-based sampling plan.

Some opinions of EFSA on fatty acids are also important. In 2012, the EFSA NDA Panel published an opinion on the Tolerable Upper Intake Level of eicosapentaenoic acid (EPA), docosahexaenoic acid (DHA) and docosapentaenoic acid (DPA). The Panel concluded that "Supplemental intakes of EPA and DHA combined at doses up to $5 \mathrm{~g} /$ day, and supplemental intakes of EPA alone up to $1.8 \mathrm{~g} /$ day, do not raise safety concerns for adults. ... Supplemental intakes of DHA alone up to about $1 \mathrm{~g} /$ day do not raise safety concerns for the general population. No data are available for DPA when consumed alone". This was an important development as the German Federal Risk Assessment Agency (Bundesinstitut für Risikobewertung, $\mathrm{Bfr}$ ) had established a level of $1.5 \mathrm{~g} /$ day as the upper intake level for omega-3 fatty acids (BfR, 2009). While the opinion of the EFSA NDA Panel is not binding, it is an influential signpost for safety discussions with Member States; and has had as a consequence that no EU limit on omega-3 of fatty 
acids has been set under Reg. (EC) No. 1925/2006. Therefore, those dealing with omega-3 should be familiar with its existence and contents.

In terms of hygiene of fish oil for human consumption, and specifically for rancidity, an important reference is the EFSA BIOHAZ Panel opinion of 2010 (EFSA BIOHAZ, 2010). Although it did not lead to a change in Reg. (EC) No. 853/2004, it does provide useful information. EFSA opinions (EFSA CONTAM Panel, 2016, 2018) have been delivered on other issues related to contaminants in oils such as 3-monochloropropane diol and its fatty acid esters, and have led to changes in the EU regulation on contaminants (Reg. (EC) No. 1881/2006). It is perhaps an obvious, but sometimes overlooked, principle, that EU food law (article 14 of Reg. (EC) No. 178/2002) imposes an obligation on food business operators to ensure food safety, which implies addressing known contaminants, even in the absence of regulated limits.

At the same time, in any globalised industry as the lipid industry is, it is important to understand that EU rules on matters of hygiene, safety and traceability do not cease to apply at the EU borders, if the raw material is to be imported into the European Union for food use. Importers should be aware, and ensure the application of such obligations to the entire supply chain, even if located in other corners of the world.

\section{Conclusions}

EU law provides both opportunities and challenges for lipids. Most significantly, omega-3 fatty acids enjoy several health claims; nevertheless, no new application has been submitted in recent years, and positive assessments have relied on essentiality, not on new science from randomised controlled trials. The novel foods regulation does slow innovation, but provides legal certainty across the $\mathrm{EU}$, on top of proprietary data protection; assessment of novel food status should be integral to research and development. Claims related to environmental benefits, like beauty claims, are important, but do not have a clear legal framework. The new regulation on trans fatty acids does require some attention in its initial implementation. Knowledge of applicable EU law is important to inform feasibility and deployment of new products with oils and lipids.

\section{Disclosure}

The author is a consultant to food businesses, although not specifically to suppliers or manufacturers of fats and oil.

Acknowledgements. I would like to thank Mr Ignace Debruyne for the invitation to develop the contents, which form a part of the present article, for the "Practical Short Course: Nutritional \& Functional Lipids-Characteristics and Applications in Food Systems" held in Frankfurt (Germany) on November 29-30, 2018.

\section{References}

BfR (Bundesinstitut fur Risikobewertung). 2009. Fur die Anreicherung von Lebensmitteln mit Omega-3-Fettsauren empfiehlt das BfR dia Festsetzung von Hochstmengen. Stellungnahme Nr. 030/2009, $10 \mathrm{p}$.

EC (European Commission). 2012. Guidance document for competent authorities for the control of compliance with EU legislation on: Regulation (EU) No. 1169/2011 of the European Parliament and of the Council of 25 October 2011 on the provision of food information to consumers, amending Regulations (EC) No. 1924/2006 and (EC) No. 1925/2006 of the European Parliament and of the Council, and repealing Commission Directive 87/250/EEC, Council Directive 90/496/ EEC, Commission Directive 1999/10/EC, Directive 2000/13/EC of the European Parliament and of the Council, Commission Directives 2002/67/EC and 2008/5/EC and Commission Regulation (EC) No.608/2004 and Council Directive 90/496/ EEC of 24 September 1990 on nutrition labelling of foodstuffs and Directive 2002/46/EC of the European Parliament and of the Council of 10 June 2002 on the approximation of the laws of the Member States relating to food supplements with regard to the setting of tolerances for nutrient values declared on a label. Available at: https://ec.europa.eu/food/sites/food/files/safety/docs/labelling nutrition-vitamins_minerals-guidance_tolerances_1212_en.pdf.

EC (European Commission). 2014. Summary report of the Standing Committee on the food chain and animal health held in Brussels on 13 June 2014 (Section General Food Law). Available at: https://ec.europa.eu/food/sites/food/files/safety/docs/regcom gfl 20140613 sum.pdf.

EFSA BIOHAZ (Biological Hazards) Panel. 2010. Scientific opinion on fish oil for human consumption. Food hygiene, including rancidity. EFSA J 8(10): 1874 [48 p.]. DOI: $10.2903 /$ j. efsa.2010.1874.

EFSA CONTAM Panel (EFSA Panel on Contaminants in the Food Chain). 2016. Scientific opinion on the risks for human health related to the presence of 3- and 2-monochloropropanediol (MCPD), and their fatty acid esters, and glycidyl fatty acid esters in food. EFSA J 14(5): 4426 [159 p.]. DOI: 10.2903/j. efsa.2016.4426.

EFSA CONTAM Panel (EFSA Panel on Contaminants in the Food Chain), Knutsen HK, Alexander J, et al. 2018. Scientific opinion on the update of the risk assessment on 3-monochloropropane diol and its fatty acid esters. EFSA $J$ 16(1): 5083 [48 p.].

EFSA NDA Panel (EFSA Panel on Dietetic Products, Nutrition and Allergies). 2012. Scientific Opinion related to the tolerable upper intake level of eicosapentaenoic acid (EPA), docosahexaenoic acid (DHA) and docosapentaenoic acid (DPA). EFSA J 10(7): 2815. [48 p.] DOI: 10.2903/j.efsa.2012.2815.

EFSA NDA Panel (EFSA Panel on Dietetic Products, Nutrition and Allergies). 2016a. General scientific guidance for stakeholders on health claim applications. EFSA $J$ 14(1): 4367 [38 p.]. DOI: 10.2903/j.efsa.2016.436.

EFSA NDA Panel (EFSA Panel on Dietetic Products, Nutrition and Allergies). 2016b. Guidance on the scientific requirements for health claims related to the immune system, the gastrointestinal tract and defence against pathogenic microorganisms. EFSA J 14(1): 4369 [23 p]. DOI: 10.2903/j. efsa.2016.4369. 
Finco AMDO, Mamani LDG, Carvalho JCD, de Melo Pereira GV, Thomaz-Soccol V, Soccol CR. 2017. Technological trends and market perspectives for production of microbial oils rich in omega-3. Crit Rev Biotechnol 37(5): 656-671.

FSE (Food Supplements Europe). 2014. Guidelines for the substantiation of beauty claims for food supplements of March 2014. Available at: http://www.foodsupplementseurope.org/sites/ 0023/uploads/content/publications/beautyclaims-forfoodsupple ments.pdf? 1407341347.

GOED. 2018. GOED industry advisory: Correct expression of EPA,

DHA and total omega-3 fatty acid content in oils. Available at: https://goedomega3.com/storage/app/media/pdf/GOED\%20In dustry\%20Advisory $\% 20-\% 20$ Content $\% 20$ expression $\% 20-\%$ 202018\%2010\%2001.pdf.

Cite this article as: Bucchini L. 2019. Nutrition and health claims in Europe: oils \& fats related claims, regulatory and labeling challenges. OCL 26: 48 . 